\title{
HERMANN PAUL: um precursor da Semântica Cog- nitiva na perspectiva da língua em uso
}

\author{
Ulrike Schröder \\ (UFMG) \\ https://orcid.org/0000-0001-7764-7249
}

\section{RESUMO}

Já é vastamente conhecido que de muitos pressupostos no campo da Semântica Cognitiva existem antecipações filosóficas, antropológicas e linguísticas. Este artigo direciona seu olhar ao linguista universal Hermann Paul, cujo mérito no campo da Linguística Histórica é amplamente reconhecido, porém, sua abordagem radicalmente cognitivista e baseada na língua em uso foi e é pouco estudada até hoje. Para Hermann Paul, que participou do movimento dos neogramáticos, a metonímia representa um processo corporalmente ancorado e a metáfora, por sua vez, é vista como o caso primordial da mutação semântica. Um estudo profundo da sua obra principal, Princípios Fundamentais da História da Língua (PAUL, 1970 [1886]), revela que Paul já parte do pressuposto de que a metáfora não é uma exceção da criatividade poética, antecipando o conceito da corporificação, a ideia de mapeamento entre domínios cognitivos e das metáforas como modelos cognitivos para a explicação, compreensão e exploração do mundo cultural, assim como corroborando que a descrição da metáfora é parcial e subjetiva. Como veremos, esta obra de Paul, que representa um importante marco na história da linguística, torna-se um inigualável tesouro com inúmeros exemplos linguísticos ao ilustrar a riqueza figurativa e a vivacidade constante da nossa língua.

PALAVRAS-CHAVE: Semântica Cognitiva; neogramáticos; mutação semântica; metáfora; metonímia 


\section{HERMANN PAUL: a precursor of Cognitive Semantics from the perspective of the language in use}

\section{ABSTRACT}

It is already broadly known that many assumptions in the field of cognitive semantics have philosophical, anthropological, as well as linguistic anticipations. The following article confines its attention to the universal linguist Hermann Paul whose merit in the field of historical linguistics is widely recognized. However, his approach is equally usage-based and radically cognitive, which has been largely neglected thus far. For Hermann Paul, who participated in the Neogrammarian Movement, metonymy represents a process that is corporally entrenched and metaphor is conceived as the primary force of semantic change. A profound study of his primary work, Principles of the History of Language (1886) reveals that Paul already starts by the assumption that metaphor is not an exception of poetic creativity anticipating the concept of embodiment, the idea of mapping between two cognitive domains and that of metaphors as cognitive models for the explanation, understanding and exploration of our cultural world. Additionally, he had already contended that the description of metaphors is partial and subjective. As we will see, this key work by Paul, representing an important milestone in the history of linguistics, becomes a unique treasure of indefinite linguistic examples that illustrate the figurative richness and the constant vividness of our language.

KEYWORDS: Cognitive semantics; neogrammarian; semantic change; metaphor; metonymy

\section{Introdução}

Embora falar de uma 'Semântica Cognitiva' possa ser enganador, visto que, na Linguística Cognitiva, não se defende uma visão modular da língua, estabeleceu-se este termo para designar uma subárea de pesquisa voltada para a compreensão de teorias multifacetadas relacionadas à estruturação e à organização conceptuais de língua e sua relação 
com a experiência corporificada e cultural do homem. Ora, todas estas abordagens partem do pressuposto de que a estrutura linguística emerge do uso linguístico (usage-based model), seguindo os princípios de que: (a) sua estrutura conceptual é corporificada; (b) sua estrutura semântica está interligada à estrutura conceptual; (c) a representação do significado é enciclopédica; e (d) a construção do significado se dá por meio do processo da conceptualização (EVANS; GREEN, 2006, p. 153). A partir dessas premissas, vê-se que o axioma linguístico mais tradicional ao qual a Linguística Cognitiva se opõe é o da separação entre língua, mente e mundo. Significação não é concebida como uma reflexão objetiva de um mundo exterior, mas, sim, como uma maneira de moldar o mundo, e por conseguinte, o significado em si se torna flexível, dinâmico, variável e interdependente, inserido em nossa experiência corporal, histórica, cultural e situativa (GEERAERTS, 2006, p. 4-6).

Já é algo vastamente conhecido que muitos pressupostos e análises realizados no campo da Semântica Cognitiva têm antecipações filosóficas, antropológicas e linguísticas. ${ }^{1}$ Este artigo direcionará seu olhar ao linguista alemão Hermann Paul, cujo mérito no campo da Linguística Histórica é amplamente reconhecido, mas que raramente é visto como um importante pioneiro no campo da Semântica Cognitiva e, menos ainda, estudado com profundidade.

Após seu curso em Berlim e Leipzig, Hermann Paul foi nomeado Professor Extraordinário para Língua e Literatura Alemã na Universidade de Freiburg em 1874, instituição em que lecionou por vinte anos antes de se mudar para Munique. Sua obra Prinzipien der Sprachgeschichte (1995 $[1886])^{2}$ teve sucesso imediato, especialmente nas Europas Setentrional, Oriental e Central. O livro foi traduzido rapidamente para o inglês, tornando-se e permanecendo como uma das principais obras referenciais da Linguística Geral. Peter Auer (2007, p. 5), na inauguração do Hermann-

1 Cf., entre outros, Chamizo Dominguez e Nerlich (2010); Geeraerts (2010); Jäkel (2003); Mouton (2010); Nerlich e Clarke (2001) e Schröder (2008; 2010; 2012; 2014a, b; 2017).

2 Esta data refere-se à segunda edição. A primeira edição é de 1880, mas a seguir, sempre nos referiremos a esta segunda edição, uma vez que se trata da edição chave, como explicaremos em detalhe mais adiante. A tradução para o português que nos serviu de base, também para todas as traduções neste artigo, é a da portuguesa Maria Luísa Schemann: Princípios Fundamentais da História da Língua, Lisboa (1970). 
-Paul-Centrum für Linguistik na Albert-Ludwigs-Universität Freiburg, destacou dois aspectos da obra de Paul pouco ressaltados até então, a saber, que a abordagem dele é, sob a ótica de uma perspectiva atual, por um lado "baseada no uso (usage-based)", ${ }^{3}$ por outro lado "radicalmente cognitivista". ${ }^{4}$ Um representante da Semântica Cognitiva que de fato se dedicou à leitura de Hermann Paul é Dirk Geeraerts (2010, p. 10), que vê nele, assim como em seu colega francês Michel Bréal, uma corrente imprescindível que constituiu "a orientação psicológica da semântica histórica-filológica"5 no fim do século dezenove. E, para terminar o ciclo das avaliações da obra de Paul em direção a uma Linguística Cognitiva, no início do século vinte, a contribuição de Paul à semântica, que vai além da linguística, já era reconhecida pelo filósofo Fritz Mauthner, quem, por sua vez, se apresentava naquela época um outsider no meio acadêmico. Mauthner dedicou-se, entre outros, a um dicionário de filosofia, bem como a uma análise histórico-semasiológica da mudança do significado, entendendo a metáfora como fonte de qualquer desenvolvimento da língua, e é neste contexto que ele chama atenção para a semântica de Paul que, segundo ele, forneceu "as contribuições mais valiosas à história do pensamento humano" (MAUTHNER, 1923 [1910/11], p. 150). ${ }^{6}$

A seguir, apresentaremos em primeiro passo a localização de Hermann Paul no movimento dos neogramáticos, do qual ele fazia parte embora concomitantemente, ele tivesse ocupado uma posição marginal. $\mathrm{Na}$ parte central do artigo, trataremos do tipo de perspectiva que Paul escolhe para abordar língua em geral, dos pressupostos que formam os pilares para este ângulo e até que ponto podemos salientar correspondências com a Semântica Cognitiva antes de nos debruçarmos sobre a mutação semântica e os processos cognitivos como foram analisados por Paul. Finalmente, escrutinaremos um processo cognitivo em mais detalhe, a saber, o processo da metáfora, como pivô notável para observar como se dá o processo de mudança do significado.

\footnotetext{
3 "gebrauchsorientiert"

4 "radikal kognitivistisch"

5 "the psychological orientation of historical-philological semantics"

6 "die wertvollsten Beiträge zur Geschichte des menschlichen Denkens". Cf., para uma avaliação da contribuição de Mauthner a uma abordagem cognitiva da metáfora, Schröder (2017).
} 


\section{0 lugar de Hermann Paul no movimento dos neogramáticos}

\subsection{Os neogramáticos}

No século XIX, na Alemanha, duas correntes principais dominavam o cenário linguístico: Primeiramente, observamos a vertente romântica representada pela obra sobre as grandes tipologias do linguista e filósofo Wilhelm von Humboldt, que ponderou sobre a relação entre língua, pensamento e cultura, e advogava em prol de uma visão vitalista da língua. Em segundo lugar, a partir do descobrimento do parentesco entre as línguas clássicas (grego, latim) e o alemão, e também o sânscrito, houve um arroubo de investigações histórico-comparativas entre as gramáticas de diversas línguas, em especial entre aquelas pertencentes ao tronco indo-europeu, influenciadas pelo desejo de reconstituir a 'língua original'. A partir de uma comparação da morfologia verbal de diversas línguas, Franz Bopp (1975 [1816]), por exemplo, revelou as correspondências sistemáticas que havia entre línguas indo-europeias antigas, o que se tornou um fundamento para ilustrar empiricamente o parentesco entre elas (GARDT, 1999; FARACO, 2011; CORRÊA, 2011).

Em oposição a essa atenção dada ao passado, à escrita, à mera descrição e à busca de uma 'língua original', para os neogramáticos, por sua vez,

muito mais interessante que a reconstrução de uma suposta protolíngua seria a observação dos fenômenos que levaram à sua transformação, i.e., as infindáveis e consecutivas mudanças sofridas pelas línguas ao longo do tempo - e, ao invés de se trabalhar apenas com formas hipotéticas (por mais confiáveis que fossem), tanto melhor seria observar esses fenômenos in vivo nas línguas e dialetos à mão. (CORRÊA, 2011, p. 28)

Pertencem a este movimento, principalmente, Karl Brugmann, Hermann Osthoff, August Schleicher e Hermann Paul. A busca por uma nova linguística rigidamente metódica e estruturalista, ancorada nas Ciências Naturais, se dá com um novo objetivo: revelar as leis históricas que regem o desenvolvimento das línguas indo-europeias. Como, de forma concreta, se aplicam as Ciências Naturais à Linguística, pode ser visto a partir da teoria de August Schleicher, que propôs uma tipologia das línguas por meio de uma 'árvore genealógica' das línguas indo-europeias, ao transferir o conceito darwinista da evolução das espécies naturais às línguas. E de 
fato, uma das descobertas mais decisivas no decorrer desta aventura é que as mudanças sonoras de uma língua para a outra se dão em um processo de regularidade absoluta, o que se mostra nas leis fonéticas. Sendo assim, os neogramáticos superam a mera reconstrução de um estágio evolutivo das línguas, passando a investigar os mecanismos que estão por trás de cada mudança (GARDT, 1999, p. 278-288; FARACO 2011, p. 34-35). Tal abordagem se coloca em oposição absoluta às especulações do Romantismo, já que agora visam a descrever de modo positivista e fisiológico o mecanismo da fala. A língua não é mais concebida em termos de um sistema abstrato, mas, sim, como algo associado ao indivíduo falante, o que trilha o caminho em direção a uma orientação psicológico-subjetivista quanto à interpretação dos fenômenos da mudança linguística:

Indubitavelmente, era com entusiasmo que se investigava as línguas, porém, muito menos o indivíduo falando. O mecanismo da fala humana possui um lado duplo, um lado psíquico e um lado corporal. Um objetivo principal do linguista comparativo tem que ser descobrir o modo da sua atividade. ${ }^{7}$ (OSTHOFF; BRUGMANN, 1878, p. IV)

\subsection{0 lugar de Hermann Paul no movimento dos neogra-} máticos

Nota-se, assim, que a mudança paradigmática está, no primeiro lugar, na "primazia da língua falada sobre a escrita como principal objeto de estudo da linguística"8 (AUER, 2007, p. 3). Convém destacar esta oposição primária, uma vez que o título da obra de Hermann Paul é o que lhe atribui a alcunha de um linguista histórico, embora o método aplicado no livro, para Paul, implique debruçar-se sobre a língua real, sobre a língua em uso em oposição ao tratamento da língua em gramáticas, à língua abstrata.

Ora, especialmente a partir da segunda edição do Prinzipien der Sprachgeschichte, em oposição marcante aos outros neogramáticos, Paul aproxima-se de uma direção interacional que se reflete na sua oscilação

7 No original: "Man erforschte zwar eifrigt die sprachen, aber viel zu wenig den sprechenden menschen. Der menschliche sprechmechanismus hat eine doppelte seite, eine psychische und eine leibliche. Ueber die art seiner thätigkeit ins klare zu kommen muss ein hauptziel des vergleichenden sprachforschers sein.”

8 "Primat der gesprochenen Sprache über die geschriebene als dem eigentlichen Gegenstandsbereich der Linguistik" 
constante entre os dois polos: o individual e o social (KNOBLOCH, 2013). Paul elabora a segunda edição sob a influência da leitura de Untersuchungen über die Grundfragen des Sprachlebens de Philipp Wegener (1991 [1885]), publicado um ano antes da nova edição. ${ }^{9}$ Wegener escolhe uma ótica pragmática, fundamentando, já no final do século dezenove, uma teoria da comunicação concentrada na interação, na qual o falar e o entender são vistos como pré-condicionados por e encaixados na ação prática, dependendo da cooperação entre os interlocutores, o que acaba deixando uma forte marca na visão de Paul. Destarte, Paul integra um novo capítulo (IV) na segunda edição, introduzindo a diferenciação entre 'significado usual' e 'ocasional', entre outros, e desenvolve algumas ideias com mais profundidade, o que o leva em direção a um entendimento 'social' e mais 'pragmático' da sua teoria (HENNE; KÄMPER; OBJARTEL, 1997; NERLICH; CLARKE, 1996, p. 172). Essa incrementação acaba resultando em uma certa tensão entre as duas tendências, a visão psicológica e a visão social, algo que já se pode perceber no capítulo de introdução do livro, em que Paul localiza a linguística, diferentemente de Osthoff e Brugmann, não nas Ciências Naturais, mas nas Ciências Culturais: "A língua, como todos os produtos da cultura humana, é um objecto da contemplação histórica" (PAUL 1970 [1886], p. 13) ${ }^{10}$ e por isso, ela pertence às "ciência[s] de princípios" e não às "ciências exactas" (PAUL 1970 [1886], p. 14). ${ }^{11}$ As últimas isolam os elementos, ao passo que as Ciências Culturais buscam descobrir as forças recíprocas e as causalidades. Em busca por uma síntese, Paul (1995 [1886], p. 7) afirma que a "história da cultura" sempre representa uma ciência social e que a "história da evolução da natureza orgânica já se aproxima aliás muito, por este lado, da história da cultura" (PAUL, 1970 [1886], p. 18), ${ }^{12}$ uma tentativa ambígua para sair desse impasse.

Por último, o indivíduo é concebido como portador do desenvolvimento histórico, tendo em vista que o "que verdadeiramente se fala não sofre qualquer evolução [...] Como produto físico-fisiológico, a palavra

9 O livro nunca foi traduzido para o português. Para o título, proponho a tradução Investigações sobre as Questões Principais da Vida da Língua.

10 "Die Sprache ist wie jedes Erzeugnis menschlicher Kultur ein Gegenstand der geschichtlichen Betrachtung" (PAUL 1995 [1886], p. 2).

11 "Prinzipienwissenschaf[en]”, "Gesetzeswissenschaften" (PAUL, 1995 [1886], p. 2) 12 "Nach dieser Seite hin kommt übrigens der Kulturgeschichte schon die Entwicklungsgeschichte der organischen Natur sehr nahe.” (PAUL, 1995 [1886], p. 7) 
desaparece sem deixar vestígios mal cesse o movimento impresso aos diversos corpos" (PAUL, 1970 [1886], p. 37). ${ }^{13}$ Sendo assim, com isso, ele está em concordância com os neogramáticos, as relações linguísticas apenas são perceptíveis na fala individual. Destarte, é certo que a única realidade disponível ao pesquisador é o uso individual, e é nesse nível de consideração que as mudanças são desencadeadas, sobretudo quando usos são acrescentados a ou subtraídos do uso coletivo. Assim, por um lado, as adaptações de uma fala individual a outra fala individual e, por outro, a mudança espontânea, explicável por tensões sintagmáticas, que representam os mecanismos chave para as mudanças no uso individual de uma língua (CASTILHO, 2011, p. 64-65), como veremos mais adiante.

\section{Conceitos da Semântica Cognitiva na obra de Hermann Paul}

\subsection{Lingua, cognição e corporificação}

O dualismo cartesiano entre mente (res cogitans) e corpo (res extensa) já dominava por muito tempo não apenas as discussões filosóficas, como também as abordagens no campo da linguística, incorporado pelo gerativismo que apresentava a vertente preeminente nos anos sessenta. Com a tese da corporificação, a Linguística Cognitiva quebra com esse postulado e introduz uma nova visão ao interligar língua, corpo e mundo, partindo dos pressupostos de que: (a) a mente é inerentemente corporificada; (b) o pensamento é, em grande parte, inconsciente; e (c) os conceitos abstratos são, em sua maioria, metafóricos, tendo sua origem em nossas experiências físicas e culturais no mundo (FERRARI, 2009, p. 24). Langacker une os três domínios ao corroborar que:

Na Semântica Cognitiva, a significação é concebida como a conceptualização associada a uma expressão linguística. [...] A conceptualização fundamenta-se na realidade física: consiste em uma atividade mental que funciona como parte integrada ao corpo, que funciona como parte integral do mundo(LANGACKER, 2013, p. 4; tradução nossa). ${ }^{14}$

13 "das wirklich Gesprochene gar keine Entwickelung hat. [...] Als physiologisch-physikalisches Produkt geht das Wort spurlos unter, nachdem die dabei in Bewegung gesetzten Körper wieder zur Ruhe gekommen sind" (PAUL 1995 [1886], p. 28).

14 "In cognitive semantics, meaning is identified as the conceptualization associated with linguistic expresssion [...] conceptualization is grounded in physical 
Já no auge da produtividade intelectual alemã, logo antes de o regime nazista esvaziar o país da pesquisa acadêmica, o linguista e psicólogo alemão Karl Bühler da Escola Würzburg refere-se na sua famosa obra principal, Sprachtheorie (1982 [1934]), em primeiro lugar, a Hermann Paul, afirmando que Paul quebra com a teoria proposta por Descartes, a saber, o dualismo das substâncias, ao elaborar a linguística como uma teoria que interliga a Física com a Psicologia sem cair em solipsismo, tendo em vista que a linguística é concebida como Ciência da Cultura, e o ponto de referência é o indivíduo conversando com o outro em uma dada comunidade (BÜHLER, 1982 [1934], p. 2-3). Nesta obra, nota-se como Bühler, por sua vez adepto da Psicologia Gestalt e precursor de uma Teoria da Mesclagem metafórica (SCHRÖDER, 2010), e sempre em busca de uma síntese entre as duas grandes forças na linguística, a língua como ação e a língua como sistema, já vê em Paul este alto potencial de um linguista moderno que antecipa o conceito da corporificação. E, de fato, podemos facilmente reconhecer as paralelas entre a teoria de Paul e a Semântica Cognitiva se considerarmos que expressões da época como o elemento psíquico ou o espírito humano teriam que ser substituídos por cognição, na terminologia atual, quando se lê:

O elemento psíquico é o facto mais essencial de todo o movimento cultural, em torno do qual tudo se move, e a psicologia é a base mais nobre de todas as ciências culturais tomadas no seu sentido mais elevado. Mas nem por isso o factor psíquico é o único; não há nenhuma cultura que tenha uma base puramente psíquica [...] Logo que penetramos no domínio da evolução histórica, tanto temos que lidar com forças psíquicas como com forças físicas. O espírito humano tem que colaborar sempre com o corpo humano e com a natureza que o rodeia para criar um produto cultural seja ele qual for... (PAUL, 1970 [1886], p. 17-18, itálico do original). ${ }^{15}$

reality: it consists in activity of the brain, which functions as an integrate part of the body, which functions as an integral part of the world."

15 Das psychische Element ist der wesentlichste Faktor in aller Kulturbewegung, um den sich alles dreht, und die Psychologie ist daher die vornehmste Basis aller in einem höheren Sinne gefassten Kulturwissenschaft. Das Psychische ist darum aber nicht der einzige Faktor; es gibt keine Kultur auf rein psychischer Unterlage [...] Sowie wir das Gebiet der historischen Entwicklung betreten, haben wir es neben den psychischen mit physischen Kräften zu tun. Der menschliche Geist muss immer mit dem menschlichen Leibe und der umgebenden Natur zusammenwirken, um irgend ein Kulturprodukt hervorzubringen..." (PAUL, 1995 [1886], p. 6). 
Um exemplo dessa correspondência entre Linguística Cognitiva e a convicção de Hermann Paul de que não há uma separação entre os domínios 'língua', 'cognição' e 'mundo', e de como essa questão se reflete no postulado da inseparabilidade dos módulos da sintaxe e da semântica encontra-se no capítulo VI Fundamentos sintácticos da língua ${ }^{16}$ bem como no capítulo XV Categoria Psicológica e Gramatical. ${ }^{17}$ Na nota de rodapé em $\$ 90$ (PAUL, 1995 [1886], p. 130), Paul discute a noção de oração de acordo com Wilhelm Wundt, que defende um conceito oracional inerente, sem referência extralinguística, ao qual Paul se opõe explicitamente, estipulando que é inerente à língua sempre precisar considerar algo além dela que não é pré-dado a partir das palavras. Mais tarde, no capítulo $\mathrm{XV}$, a partir do §180, Paul delineia uma visão mais profunda dessa ideia, partindo do pressuposto de que "Toda a categoria gramatical se cria com base numa categoria psicológica. [...] A categoria gramatical é, de certo modo, uma congelação da categoria psicológica." (PAUL, 1970 [1886], p. 279)..$^{18}$ De maneira muito mais avançada, porém, no entanto, partindo da mesma hipótese principal, Langacker (2013, p. 98) descreve as categorias gramaticais em termos semânticos, com relação ao nível prototípico, bem como ao nível esquemático, quando destaca: "o que determina a categoria gramatical de uma expressão não é seu conteúdo conceptual em geral, mas particularmente a natureza do seu perfil". ${ }^{19}$

\subsection{0 significado usual e ocasional no processo da mutação} semântica

Como já apontado anteriormente (GARDT, 1999, p. 285), o capítulo IV Mutação semântica (PAUL, 1970 [1886]), ${ }^{20}$ que apenas foi inserido na segunda edição, era também produto da leitura que Paul fez de Philipp Wegener. Influenciado por Wegener, neste novo capítulo, Paul introduz a diferença entre a significação usual e ocasional ao interligar esta distinção com a mudança semântica. A significação usual refere-se ao uso conven-

\section{Die syntaktischen Grundverhältnisse \\ 17 Psychologische und grammatische Kategorie}

18 Jede grammatische Kategorie erzeugt sich auf Grundlage einer psychologischen. [...] Die grammatische Kategorie ist gewissermassen eine Erstarrung der psychologischen" (PAUL, 1995 [1886], p. 263).

19 "what determines an expression's grammatical category is not its overall conceptual content, but the nature of its profile in particular".

20 no original: Wandel der Wortbedeutung (PAUL, 1995 [1886]). 
cionalizado, lexicalizado, como diríamos hoje. Nas palavras de Paul, tal significação refere-se ao "conteúdo ideológico que se relaciona com uma palavra para os indivíduos duma entidade linguística". Já como significação ocasional, o autor entende "aquele conteúdo ideológico que a pessoa que fala relaciona com a palavra ao pronunciá-la, e que ela espera que também o ouvinte relacione com a mesma palavra" (PAUL, 1970 [1886], p. 83). ${ }^{21}$ Destarte, o significado ocasional constitui-se a partir do uso situacional, individual e contextualizado.

Ora, de acordo com Paul, a necessidade de mudança do significado é consequência da compreensão psicológica da língua: tendo em vista que significados não são transmitidos, mas apenas são evocados no ouvinte, $\mathrm{o}$ falante espera que o ouvinte associe ao dito o mesmo conteúdo ideológico que ele associou. Não obstante, como sempre há uma discrepância entre os dois significados - o do falante e o do ouvinte - este desvio forma a base para uma mudança semântica progressiva: ${ }^{22}$

Em todos os desvios da significação ocasional em relação à usual há um começo de mutação semântica. Mal começam a repetir-se com uma certa regularidade, o individual e momentâneo tornam-se gradualmente geral e usual (PAUL, 1970 [1886], p. 91-92). ${ }^{23}$

É justamente nesta dinâmica existente entre os dois usos que Paul localiza, então, a grande variedade de significados que uma palavra pode ganhar. Com isso, ele antecipa boa parte do conceito da polissemia, não apenas no sentido de uma palavra apresentar múltiplos significados concomitantemente interligados. Além disso, Paul enquadra-se na suposição dos cognitivistas de que a polissemia vem a ser um processo chave que revela processos em comum entre a organização lexical, morfológica e

21 "Vorstellungsinhalt, der sich für den Angehörigen einer Sprachgenossenschaft mit einem Worte verbindet [...] denjenigen Vorstellungsinhalt, welchen der Redende, indem er das Wort ausspricht, damit verbindet und von welchem er erwartet, dass ihn auch der Hörende damit verbinde.” (PAUL, 1995 [1886], p. 75). 22 Corrêa (2011) vê neste processo de mutação semântica, que pressupõe um desvio no emprego social, um dos principais pontos em comum entre Paul e os sociolinguistas variacionistas.

23 No original: "In allen besprochenen Abweichungen der okkasionellen Bedeutung von der usuellen liegen Ansätze zu wirklichem Bedeutungswandel. Sobald sie sich mit einer gewissen Regelmäßigkeit wiederholen, wird das Individuelle und Momentane allmählich generell und usuell” (PAUL, 1970 [1886], p. 84). 
sintática, como veremos mais adiante. Sendo assim, Paul destaca o que hoje chamaríamos de cenário, e também o contexto em que a palavra se insere, bem como o usuário desta palavra para quem o emprego dela varia em dependência do seu domínio específico:

É muito diferente se ouço a palavra Blatt (folha) durante um passeio pela floresta ou numa loja de objectos de arte, onde vejo gravuras ou fotografias, ou num café onde se fala de jornais; assim também se ouço a palavra Band (fita, arco, tomo) numa retrosaria, ou numa tanoaria, ou numa biblioteca. Quando um carpinteiro, um caçador, um médico ou outras pessoas das mais diversas profissões conversar umas com as outras, têm a tendência para interpretar todas as palavras segundo o aspecto que mais se aproxima do seu ofício. De grande importância é o contexto em que uma palavra aparece. (PAUL, 1970 [1886], p. 89) ${ }^{24}$

Em muitos momentos, a terminologia de Paul até mostra paralelas contundentes com o conceito de 'rede radial' (radial network): recorrendo a Lakoff (1987), Pörings e Schmitz (2003, p. 34-38) ilustram a partir da palavra Schule as extensões do significado central esquemático e prototípico que se referem à ideia da instituição. As extensões compreendem uma rede radial composta por quatro processos cognitivos distintos: (a) metaforização (p. ex. 'escola da vida'); (b) metonimização (p. ex. 'prédio'); (c) generalização (p. ex. 'corrente artística'); e (d) especificação (p. ex. 'curso específico'). Paul já considera e interliga todos esses processos, embora dedique uma atenção especial à metáfora.

É no relatório Ueber die Aufgaben der wissenschaftlichen Lexikographie mit besonderer Rücksicht auf das deutsche Wörterbuch (1894) ${ }^{25}$ que Paul explica a diferença entre extensão e restrição do significado como processos de mutação semântica. Enquanto a restrição consiste na

24 "Es macht einen grossen Unterschied, ob ich das Wort Blatt bei einem Spaziergang im Walde höre oder in einer Kunsthandlung, wo ich mir Stiche oder Photographien besehe, oder in einem Caféhause, wo über Zeitungen gesprochen wird; ebenso ob ich das Wort Band in einem Posamentiergeschäft höre oder in einer Böttcherei oder in einer Bibliothek. Unterhalten sich Tischler, Jäger, Ärzte oder sonst Leute von einerlei Beruf untereinander, so sind sie dazu disponiert alle Wörter von derjenigen Seite her aufzufassen, die ihnen dieser Beruf nahe legt. Von grosser Bedeutung ist die Verbindung, in der ein Wort auftritt." (PAUL, 1995 [1886], p. 81)

25 Sobre as tarefas da lexicografia científica com consideração especial do dicionário alemão (tradução nossa). 
entrada de uma nova acepção no significado ocasional que normalmente não é exprimida pela palavra, a extensão do significado compreende acepções já presentes no significado dado, sendo que algumas dessas acepções somem. O que também acontece é que nem todos os aspectos do significado da palavra, mas apenas uma parte deles, se tornam relevante para o falante e o ouvinte. Sendo assim, também este tipo de mudança nasce como significado ocasional (PAUL, 1894, p. 72-73). Como exemplo para a extensão do significado, o que corresponderia à generalização nos termos de Pörings e Schmitz, Paul recorre, entre outros, à palavra fertig ("pronto"), que primeiramente se restringiu ao significado de "preparado para uma viagem', antes de a referência a estar preparado aflorar para o primeiro plano, deixando em segundo plano o passeio (PAUL, 1995 [1886], p. 91; PAUL 1970 [1886], p. 98). Já acerca da restrição do significado, isto é, a respeito da especificação, na terminologia de Pörings e Schmitz, Paul (1995 [1886], p. 87-88) ilustra este processo por meio da palavra Schirm. ${ }^{26}$ As pessoas já não pensam mais no significado geral dessa palavra, apenas em determinada forma e função que ela teria, e em construções concretas, como se reflete nas palavras que especificam estas características: Ofenschirm ("guarda-fogo"), Lampenschirm ("quebra-luz"), Regenschirm ("quarda-chuva"), Sonnenschirm ("guarda-sol”) etc. Paul aponta que todas as expressões técnicas, bem como muitos nomes próprios de pessoas e locais provêm de denominações categoriais, como Burg ("Castelo"), Neustadt ("Cidade Nova") etc.

Quando Paul direciona seu olhar para a metonímia, ele a introduz da seguinte maneira:

Esta possibilidade [a metonímia] consiste em que qualquer coisa que, segundo a experiência geral, está ligada no espaço, no tempo ou na causa à significação usual, é compreendida juntamente com a palavra ou então exclusivamente pela mesma. Neste caso está a conhecida figura da estilística latina, pars pro toto...” (PAUL, 1970 [1886], p. 9091; acréscimo da autora) $)^{27}$

26 No livro em português, a palavra é traduzida erradamente por "pala". Não há um termo básico em português, mas a palavra mais próxima seria "blindagem". 27 no original: "Diese [die Metonymie] besteht darin, dass etwas, was mit dem usuellen Bedeutungsinhalt nach allgemeiner Erfahrung räumlich oder zeitlich oder kausal verknüpft ist, unter dem Worte mitverstanden oder auch allein darunter verstanden wird. Hierher gehört die aus der lateinischen Stilistik als pars pro toto bekannte Figur..." (PAUL 1995 [1886], p. 83; acréscimo da autora). 
Paul ressalta que o tipo de mapeamento é primeiramente de natureza espacial, temporal ou causal, e está interligado à noção básica. $\mathrm{O}$ autor dá, como exemplo, denominações de pessoas de acordo com partes corporais ou mentais que são características delas: Lockenkopf ("cabeça com cachos"), Dummkopf (“cabeça idiota"), Dickkopf, ${ }^{28}$ Grossmaul ${ }^{29}$ etc. Além disso, Paul mostra como as emoções são denominadas de acordo com suas bases físicas, os movimentos corporais, como se reflete nos verbos beben ("estremecer"), zittern ("tremer"), schauern ("arrepiar-se"), erröten ("corar"), aufatmen ("respirar fundo"), bem como em locuções verbais como die Nase rümpfen ("torcer o nariz"), die Ohren spitzen ("aguçar as orelhas"), mit den Zähnen knirschen ("ranger os dentes"), die Faust ballen ("cerrar o punho"), das Herz schlägt ihm ("o coração lhe bate"), das versetzt ihm den Atem ("isso lhe corta a respiração"), die Galle läuft ihm über ("o fel lhe extravasa") (PAUL, 1995 [1886], p. 99; PAUL, 1970 [1886], p. 107). A partir dessa origem corporal, inicia-se um processo de 'escurecimento' (Verdunkelung) do significado original e as expressões passam a se tornar designações das próprias emoções: staunen, por exemplo, significava originalmente, ainda no século XVII, "olhar fixamente para algo", mas hoje este significado já não é mais transparente, pois passou para "espantar-se com algo". Não é difícil reconhecer as paralelas entre esta abordagem de Paul e os postulados da Semântica Cognitiva: no seu livro Metaphor and Emotion (2003), Kövecses mostra como metáforas usadas para estruturar o domínio das emoções são motivadas metonimicamente pelo corpo humano, bem como por seu meio social e cultural (KÖVECSES, 2003, p. 14). De acordo com Kövecses, a metonímia apresenta uma relação stand for (uma parte corresponde à outra parte ou ao total) no mesmo domínio, ao passo que a metáfora realiza um mapeamento de um domínio para outro. Sendo assim, um elemento do domínio 'raiva' é representado pelo aumento de temperatura como reação real do corpo humano quando experiencia tal emoção, o que se reflete em expressões linguísticas como, por exemplo, he’s upset..$^{30}$ Já a reação opos-

28 literalmente: "cabeça grossa"; metaforicamente: pessoa que quer 'forçar a barra'. Tem-se o fenômeno que Goossens (1990) chama de 'metonímia na metáfora' (metonymy within metaphor), pois os dois processos se misturam.

29 literalmente: "boca grande; metaforicamente: pessoa que fala e ostenta muito, 'falador'. Conta com o mesmo processo de metonímia na metáfora.

30 "Irritado", a expressão em português não transfere a ideia metonímica do corpo que vai para cima. 
ta, uma queda da temperatura corporal, se espera no caso de medo, o que se reflete na expressão em inglês to have cold feet. ${ }^{31} \mathrm{O}$ primeiro exemplo, destarte, apresenta a metonímia conceptual PHYSICAL AGITATION STANDS FOR ANGER, ao passo que a segunda expressão apresenta a metonímia conceptual DROP IN BODY TEMPERATURE STANDS FOR FEAR (KÖVECSES, 2003, p. 5).

Paul também aponta o conceito do domínio, ou seja, o conceito do cenário, quando corrobora que procedimentos acompanhados por ações simbólicas frequentemente apenas insinuadas por expressões específicas não são mantidas quando os símbolos já caíram em desuso. Um exemplo disso seria o uso da expressão jemanden unter die Haube bringen ${ }^{32}$ para casar. (PAUL 1970 [1886], p. 107; PAUL 1995 [1886], p. 99). Adicionalmente, Paul acrescenta as relações de característica para entidades como na palavra Mehrheit ("maioria"), as designações de processos e estados derivados de verbos, como Rat ("conselho"), uma designação do resultado de um processo como Druck ("edição") ou obras pelo nome do autor ("um Goethe”) (PAUL 1970 [1886], p. 108-109; PAUL 1995 [1886], p. 99-100).

\subsection{A metáfora como caso primordial da mutação semântica}

Torna-se evidente no referido capítulo IV que, para Paul, a metáfora assume um papel chave na mudança do significado e também na determinação dos outros processos da mutação semântica delineados acima. A origem da metaforização de uma palavra, de acordo com Paul, está na necessidade de se exprimir de tal modo que, por trás de uma transição de um significado usual para um significado ocasional que ganha terreno pelo emprego repetitivo, frequentemente, está a atuação de uma metáfora enfraquecida, quase morta, não mais transparente, convencionalizada, no sentido de Lakoff e Johnson (2003 [1980]):

A metáfora é um dos meios mais importantes para a criação de nomes de complexos de ideias, para os quais não existe ainda uma designação adequada. Mas o seu emprego não se limita aos casos em que se verifica esta necessidade externa. Muitas vezes somos levados por um impulso interior a preferir uma expressão metafórica, mesmo em casos onde existe já uma designação. A metáfora é precisamente alguma coisa que brota necessariamente da natureza humana e se impõe não só na linguagem poética, como sobretudo também na linguagem corrente popular, que tende sempre para a plasticidade e caracterização drástica.

31 Literalmente "ter pés frios", o que significa 'perder a coragem'.

32 Literalmente 'colocar alguém debaixo da touca'. 
Também destas metáforas muitas se tornam usuais, embora não tão facilmente como nos casos em que não dispomos doutra designação. (PAUL 1970 [1886], p. 102) $)^{33}$

Nesta citação, ainda mais paralelas com a Teoria da Metáfora Conceptual (TMC), além da corporificação, vêm à luz e revelam o caráter cognitivo da abordagem de Paul, já a partir do termo Vorstellungskomplex ("complexos de ideias"), um equivalente da época de Paul para a ideia do domínio cognitivo. Se recorremos a Jäkel (2003, p. 40-41), que estabelece dez teses centrais da TMC, notamos que já nesta citação, Paul afirma, implícito ou explicitamente que a metáfora não é uma exceção da criatividade poética ou da retórica (Tese da Ubiquidade), e que metáforas formam modelos cognitivos com estruturas da organização do conhecimento (Tese do Modelo), o que se relaciona à ideia de que a metáfora serve para a explicação, compreensão e exploração do mundo social (Tese da Necessidade), além de que ela dá abertura para inúmeros novos caminhos de pensamento (Tese da Criatividade). Finalmente, Jäkel frisa que a TMC ressalta a importância de estudos sobre o desenvolvimento histórico de metáforas conceptuais, pois são estes estudos que conseguem revelar as mudanças do pensamento ao longo do tempo (Tese da Diacronia). Já nesta citação, então, são cinco teses da TMC que correspondem à visão de Paul. Adicionalmente, Paul destaca na parte sobre "a linguagem corrente popular, que tende sempre para a plasticidade e caracterização drástica" que não apenas pretende observar a língua em uso, mas, mais especificamente, a língua falada e até gíria, como se revela em outros momentos de sua obra, quando explica que, ao chamarmos alguém Schwein ("porco"), não se trata de uma equação matemática com resultado único e inequívoco, mas, sim, apenas de uma seleção parcial deste complexo de ideias

33 No original: "Die Metapher ist eines der wichtigsten Mittel zur Schöpfung von Benennungen für Vorstellungskomplexe, für die noch keine adäquaten Bezeichnungen existieren. Ihre Anwendung beschränkt sich aber nicht auf die Fälle, in denen eine solche äussere Nötigung vorliegt. Auch da, wo eine schon bestehende Benennung zur Verfügung steht, treibt oft ein innerer Drang zur Bevorzugung eines metaphorischen Ausdrucks. Die Metapher ist eben etwas, was mit Notwendigkeit aus der menschlichen Natur fliesst und sich geltend macht nicht bloss in der Dichtersprache, sondern vor allem auch in der volkstümlichen Umgangssprache, die immer zu Anschaulichkeit und drastischer Charakterisierung neigt. Auch hiervon wird vieles usuell, wenn auch nicht so leicht wie in den Fällen, wo der Mangel an einer andern Bezeichnung mitwirkt" (PAUL, 1995 [1886], p. 94-95). 
que compõe a noção de Schwein, como, por exemplo: "ele é obsceno como um porco" (PAUL, 1995 [1886], p. 83; PAUL 1970 [1886], p. 90). Paul também aponta o fato de que domínios integrais podem passar por uma mudança de significado, como mostram expressões ligadas a partes do corpo, como por exemplo, à mão: auf der Hand liegen (lit.: "estar na mão": 'estar-se mesmo a ver'), an die Hand geben (lit. "dar à mão": 'sugerir', 'ajudar'), von der Hand weisen (lit. "tirar da mão": 'negar') etc. (PAUL, 1970 [1886], p. 112; PAUL 1995 [1886], p. 103). Ora, é bastante elucidativa a abundância de exemplos elencada por Paul (1995 [1886], p. 95-97; PAUL, 1970 [1886], p. 102-105), o que ilustra que o motivo principal para o uso da metáfora, assim como postula a TMC, está na experiência do ser humano e na sua interação com o mundo que o cerca, como se pode ver a partir da comparação das obras de Paul e de Lakoff e Johnson: ${ }^{34}$

- Semelhança quanto à forma externa: Löwenzahn ("dente de leão")

- Semelhança quanto à função: Fuss eines Tisches ("pé de mesa")

- Analogia entre a extensão espacial e a temporal: Zeitabschnitt ("período de tempo")

THE TIME ORIENTATION METAPHOR (LAKOFF; JOHNSON, 1999, p. 140)

- Mapeamento de expressões de movimento para tempo: die Zeit vergeht ("o tempo passa")

THE MOVING TIME METAPHOR (LAKOFF; JOHNSON, 1999, p. 141)

- Mapeamento de expressões espaciais para intensidade: grosse Hitze ("grande calor")

SIGNIFICANT IS BIG (LAKOFF; JOHNSON, 2003 [1980], p. 50)

- Mapeamento de relações espaciais exteriores a relações interiores: ein Gedanke geht mir durch den Kopf ("um pensamento me passou pela cabeça")

MIND AS A CONTAINER (LAKOFF; JOHNSON, 1999, p. 338)

- Mapeamento das atividades corporais a atividades espirituais: leiten ("guiar")

PURPOSES ARE DESTINATIONS (LAKOFF; JOHNSON, 1999, p. 190)

- Entendimento de estados como espaço: in Gedanken versunken ("mergulhado em pensamentos")

STATES ARE CONTAINERS (LAKOFF; JOHNSON, 2003 [1980], p. 33-34)

34 Uma parte dessa lista encontra-se também em Schröder (2012, p. 194-195). 
- $\quad$ Entendimento de mudanças de estados como movimento: vom Hass zur Liebe übergehen ("passar do ódio ao amor")

STATES ARE LOCATIONS / CHANGES ARE MOVEMENTS (LAKOFF;

JOHNSON, 1999, p. 179)

- Mapeamento de uma experiência sensorial para outra: schreiende Farben ("cores berrantes")

- Mapeamento de experiência sensorial para percepções mentais: vorsehen ("prever")

KNOWING IS SEEING METAPHOR (LAKOFF; JOHNSON, 1999, p.

53-54)

- Mapeamento de atividades a coisas: die Erde trinkt Feuchtigkeit ("a terra bebe a humidade")

PERSONIFICATION (LAKOFF; JOHNSON, 2003 [1980], p. 33-34)

Ora, Paul vai além de Lakoff e Johnson e, com isso, intervém diretamente nas discussões atuais que tocam em questões socioculturais e discursivas da metáfora ao questionar o cognitivismo individualista e a ausência de estudos empíricos relacionados à língua em uso, como era frequente nas abordagens da primeira geração da TMC. Paul assinala o papel da variedade cultural e individual na construção metafórica da realidade, ao dizer:

Assim, por meio de algo que nos está mais próximo, tornamos mais plástico e mais familiar aquilo que é estranho à nossa compreensão e interesse, por isso, na escolha da expressão metafórica manifestam-se as diferenças dos interesses individuais, e no conjunto das metáforas que passaram a fazer parte do uso duma língua podemos reconhecer quais os interesses que predominaram nesse povo. (PAUL, 1970 [1886], p. 102) $)^{35}$

De forma implícita, nesta citação está inerente mais uma das teses de Jäkel (2003, p. 40-41), a saber, a Tese de Focalização, o que Lakoff e Johnson (2003 [1980], p. 10-13, 67) chamam de highlighting e hiding: a descrição da metáfora é parcial, ou seja, subjetiva. Ela destaca certos aspectos do domínio-alvo e esconde outros. Outra força motriz para a

35 "Das dem Verständnis und Interesse ferner liegende wird dabei durch etwas Näherliegendes anschaulicher und vertrauter gemacht. In der Wahl des metaphorischen Ausdruckes prägt sich daher die individuelle Verschiedenheit des Interesses aus, und an der Gesamtheit der in einer Sprache usuell gewordenen Metaphern erkennt man, welche Interessen in dem Volke besonders mächtig gewesen sind." (PAUL, 1995 [1886], p. 95) 
variedade e a espontaneidade na criação da mutação semântica a partir da metáfora encontra-se na fala cotidiana relacionada ao exagero, como atesta Paul com base em expressões hiperbólicas tais como Berge von Leichen ("montes de cadáveres"), ein Strom von Tränen ("uma torrente de lágrimas"), das dauert eine Ewigkeit ("isto demora uma eternidade"), endlos ("infinito"), sich tot lachen ("morrer de rir") ou ich sterbe vor Langeweile ("morro de tédio"). Neste processo, a metáfora, muitas vezes, é acompanhada por um processo da extensão do significado, com isso, palavras que denotam algo negativo passam por uma generalização, como, por exemplo, Dreck ("porcaria"), que é usado para toda espécie de sujeira e também para denotar uma pessoa, como em Dreckskerl ("cara de merda"). Da mesma forma, em um processo invertido, um adjetivo como schön ("belo") pode ser mapeado do domínio da beleza para outros domínios, sendo também empregado de forma irônica em uma frase como das ist ja eine schöne Geschichte ("isso é mesmo uma bela história"; PAUL, 1995 [1886], p. 101-102; PAUL, 1970 [1886], p. 110-111).

Como a obra Princípios Fundamentais da História da Língua apresenta uma visão talentosamente holística da linguagem, Paul não deixa de retomar o tópico da metáfora em outros capítulos nos quais se dedica a questões morfossintáticas. São estes os capítulos XII Influência da modificação de função sobre a formação por analogia, ${ }^{36}$ XIX Origem da formação de palavras e da flexão ${ }^{37}$ e XX $A$ divisão das partes do discurso. ${ }^{38}$ Já realçamos anteriormente que Paul, em sintonia com os representantes da Semântica Cognitiva, defende a ubiquidade da metáfora no cotidiano, ou seja, ela não se restringe ao discurso poético e retórico. Agora, Paul observa dois processos de mudanças de significado, sendo o primeiro uma 'queda' de uma metáfora poética já desgastada para um uso convencional no qual se torna cada vez menos transparente, como ilustrado na expressão in Liebe zu jemand entbrannt sein ("estar inflamado de amor por alguém"). Já o segundo processo se dá na fala prosaica comum, e é neste caso que entra a morfossintaxe, pois, frequentemente, esta mutação é acompanhada por uma mudança de classe de palavra que tem consequências para o significado:

36 Einfluss der Funktionsveränderung auf die Analogiebildung

37 Entstehung der Wortbildung und Flexion

38 Die Scheidung der Redeteile 
Aqui a troca de construção é um critério infalível de desaparecimento gradual da significação básica. Sobretudo exprime-se nela frequentemente a separação da percepção material que originariamente lhe esteve na base (PAUL, 1970 [1886], p. 251). ${ }^{39}$

Como exemplo, Paul refere-se a "compostos com advérbios de lugar" como, entre outros, einwirken ("influenciar") e Einwirkung ("influência"), que se formaram com base na junção do verbo wirken ("atuar") e da preposição in ("em"). Hoje, estuda-se na Linguística este fenômeno da língua alemã sob o rótulo de verbos separáveis e verbos não separáveis para se referir a este tipo de prefixo preposicional, também frequente em inglês, analisado com profundidade no campo da Semântica Cognitiva desde o estudo sobre a polissemia de over apresentado por Brugman e Lakoff (1988). Bellavia (2007, p. 132-145) demonstrou em um estudo detalhado a complexidade da morfologia alemã e sua interligação com a semântica, uma vez que, além da quantidade alta de preposições, observam-se três possibilidades da preposição, seja como partícula, seja como composto com preposição separável, seja com preposição não separável. Neste último caso, geralmente, o sentido metafórico encontra-se em estágio mais avançado, como se mostra nos verbos que têm dois significados em dependência do acento focal da palavra, algo que indica quando se trata do verbo com prefixo separável ou não. Sendo assim, überlegen (separável) significa "cobrir" (Ich lege mir den Mantel über: "Eu me cobro com o casaco"), mas überlegen (inseparável) significa "pensar" (Ich überlege, was ich morgen mache: "Eu penso sobre o que vou fazer amanhã"). O próprio Paul já mostra esta tendência a partir do desenvolvimento distinto do verbo acompanhado de advérbio de lugar heran kommen em oposição ao verbo ankommen. Enquanto heran kommen" ("aproximar-se") tem um significado meramente espacial, ankommen (“chegar") já é usado no sentido mais geral, e até metafórico. Já verbos como vorwerfen (lit. "jogar algo na frente de alguém”: 'acusar alguém de algo') têm origem menos transparente, sendo que esta intransparência aumenta ainda

39 No original: "Hier ist der Konstruktionswechel ein untrügliches Kriterium für das Verblassen der Grundbedeutung. Namentlich bekundet sich darin häufig die Loslösung von der ursprünglich zu Grunde liegenden sinnlichen Anschauung." (PAUL, 1995 [1886], p. 237).

40 Hoje, este verbo é escrito como uma palavra só e faz parte do grupo dos verbos separáveis: herankommen. 
mais quando o verbo muda de classe e se torna um composto nominal: Vorwurf ("acusação"; PAUL, 1995 [1886], p. 340; PAUL, 1970 [1886], p. 260-261).

Muitas vezes, para a criação de um composto, necessita-se de um certo grau de 'isolação', o que, de acordo com Paul, representa um conceito chave na história da língua, e indica o caminho do nível sintático para o nível morfológico. Há duas opções: ou o todo pode sofrer uma evolução de que as partes isoladas não compartilham, ou, pelo contrário, pode ser que as várias partes sofram uma evolução que não atinja o todo. Se algum desses casos ocorrer, é possível que haja a transformação de uma estrutura sintática em um composto e a isolação geralmente se inicia assim que a estrutura sintática receber um conteúdo semântico que já não coincide integralmente com o que se compõe pela associação dos vários elementos (PAUL, 1970 [1886], p. 352; PAUL, 1995 [1886], p. 330). Isto se reflete de forma mais nítida em compostos metafóricos como, por exemplo, Lebensabend (lit. "noite da vida" = 'idade avançada'), Unternehmensseele (lit. "alma da empresa"), Seelöwe, ("leão-marinho"), Bienenkönigin ("abelha-rainha") etc. (PAUL, 1995 [1886], p. 335). No que diz respeito à mudança de classe de palavra, um caminho que vai do verbo ao substantivo é aquele do nomens agentis ao nomens actionis, que tem origem na metáfora por compreender a atividade como uma entidade que pode ser momentânea ou permanente: die Befreiung aus der Not ("a liberação do sofrimento"), die Erziehung des Kindes ("a educação da criança"). Já no segundo caso, há uma perda da característica do nomens actionis, que é substituído por um estado permanente, como se reflete nas derivações Besinnung ("consciência"), Bewegung ("movimento"), Verfassung ("constituição"). Finalmente, "pela continuação da isolação pode fazer-se desaparecer por completo todo e qualquer vestígio da origem verbal" (PAUL, 1970 [1886], p. 383). ${ }^{41}$ Destarte, chega-se em entidades nas quais o verbo não é mais transparente como Haltung ("atitude"), Gleichung ("equação") ou Rechnung ("conta").

\section{Considerações finais}

Como correspondia mais ao ideal de sua época, Hermann Paul foi o que se pode chamar um 'linguista universal', um estudioso que se

41 No original: "durch weitere Isolierung kann dann jede Spur des verbalen Ursprungs vernichtet werden” (PAUL, 1995 [1886], p, 364). 
dedicava a estudos filológicos, linguísticos, gramaticais, a investigações do alto-alemão médio e da lexicografia alemã. A obra Princípios Fundamentais da História da Língua apresenta um inigualável tesouro de inúmeros exemplos linguísticos que ilustram os caminhos virtuosos, aleatórios, sinuosos e imprevisíveis que o desenvolvimento da língua pode escolher, bem como a riqueza figurativa e a vivacidade constante da nossa língua. Atualmente, nós, linguistas, somos cada vez mais especializados em uma área específica e, perante a complexidade crescente de questões linguísticas que podem ser analisadas, raramente encontram-se pesquisadores com formação holística. As possibilidades de pesquisa também têm se expandido devido às tecnologias que não estavam à disposição no final do século dezenove. Os neogramáticos e, junto a eles, Hermann Paul provavelmente teriam se entusiasmado com nossos corpora de conversas autênticas gravadas ou filmadas e transcritas de acordo com convenções baseadas em símbolos detalhados que tentam explicitar na escrita cada aspecto prosódico, bem como com os programas para captação de som e imagem e os sistemas para transcrição de gestos, desenvolvidos recentemente. Hoje em dia, o espírito anglo-americano do empirismo venceu a corrida científica mundial em termos de pesquisa linguística, área direcionada sobretudo a estudos empíricos, sejam eles de cunho experimental, etnográfico ou conversacional.

Entretanto, o que às vezes é deixado de lado, tendo em vista essa volta ao objeto de estudo in situ, é a discussão teórica e historiográfica da linguística. Nunca deveríamos esquecer que somos "anões nos ombros de gigantes". A frase, atestada pela primeira vez por Bernardo de Chartres em 1120, determina a relação entre ciência e tradição, ou seja, entre ciência e os méritos das gerações anteriores. Nesta visão, pesquisadores que estão cientes dos precursores consideram-se anões que se beneficiam do trabalho e do desempenho dos pioneiros por acrescentar sua própria contribuição ao conhecimento pré-dado e é somente a partir disso que nasce e se desenvolve o progresso. Lançar pontes para o passado, portanto, sempre deve ser uma meta por direito próprio, indispensável, da historiografia linguística. 


\section{REFERÊNCIAS}

AUER, Peter. Hermann Pauls radikaler Kognitivismus. Versuch einer Neubewertung. Vortrag zur Eröffnung des HPCL, Freibung, 18. Mai 2007, 1-10. Disponível em: < http://www.hpcl.uni-freiburg.de/assets/files/hermann_paul/hermann_pauls_radikaler_kog-nitivismus.pdf>; acesso em: 05/01/2019.

BELLAVIA, Elena. Erfahrung, Imagination und Sprache. Die Bedeutung der Metaphern der Alltagssprache für das Fremdsprachenlernen am Beispiel der deutschen Präpositionen. Tübingen: Gunter Narr, 2007.

BOPP, Franz. Über das Conjugationssystem der Sanskritsprache in Vergleichung mit jenem der griechischen, lateinischen, persischen und germanischen Sprache. Hildesheim, New York: Olms, 1975 [1816].

BRUGMAN, Claudia; LAKOFF, George. Cognitive topology and lexical networks. In: SMALL, Steven L.; COTTRELL, Garrison W.; TANENHAUS, Michael K. (Org.). Lexical Ambiguity Resolution: Perspectives from Psycholinguistics, Neuropsychology, and Artificial Intelligence. San Mateo: Morgan Kaufmann, 1988. p. 477-508.

BÜHLER, Karl. Sprachtheorie: die Darstellungsfunktion der Sprache. Stuttgart: Fischer, 1982 [1934].

CASTILHO, Ataliba Teixeira. Representações das categorias cognitivas e sua diacronia. Interface Linguística cognitiva - Linguística histórica. Filologia e Linguística Portuguesa, v.13, n.1, p. 63-87, 2011.

CHAMIZO DOMINGUEZ, Pedro José; NERLICH, Brigitte. Metaphor and truth in Rationalism and Romanticism. In: BURKHARDT, Armin; NERLICH, Brigitte. (Org.). Tropical Truth(s). The Epistemology of Metaphor and other Tropes. Berlin, New York: De Gruyter, 2010. p. 51-72.

CORRÊA, Elisa Figueira de Souza. A ideia de mudança em Hermann Paul e seu legado no gerativismo e na sociolinguística variacionista. Revista Diadorim, v.8, p. 27-42, 2011.

EVANS, Vyvyan; GREEN, Melanie. Cognitive Linguistics. An Introduction. Edinburgh: Edinburgh University Press, 2006.

FARACO, Carlos Alberto. Estudos pré-saussuriano. In: MUSSALIM, Fernanda; BENTES, Anna Christina (Org.). Introdução à linguística 3. Fundamentos epistemológicos. São Paulo: Cortez, 2011, p. 22-51.

FERRARI, Lilian Vieira. A Linguística Cognitiva e o realismo corporificado: Implicações filosóficas e psicológicas. Veredas: revista de estudos linguísticos, v.5, n.2, p. 23-29, 2009. 
GARDT, Andreas. Geschichte der Sprachwissenschaft in Deutschland. Vom Mittelalter bis ins 20. Jahrhundert. Berlin, New York: Walter de Gruyter, 1999. GEERAERTS, Dirk. A rough guide to Cognitive Linguistics. In: GEERAERTS, Dirk (Org.), Cognitive Linguistics: Basic Readings. Berlin, New York: Mouton de Gruyter, 2006. p. 1-28.

GEERAERTS, Dirk. Theories of Lexical Semantics. Oxford, New York: Oxford University Press, 2010.

GOOSSENS, Louis. Metaphtonymy: The interaction of metaphor and metonymy in expressions for linguistic action. Cognitive Linguistics, v.1, p. 323-340, 1990. HENNE, Helmut; KÄMPER, Heidrin; OBJARTEL, Georg. Das Wörterbuch im Visier - Hermann Pauls systematische Arbeit. 100 Jahre Deutsches Wörterbuch (1897-1997). Zeitschrift für germanistische Linguistik, v.25, p. 167-198, 1997.

JÄKEL, Olaf. Wie Metaphern Wissen schaffen: die kognitive Metapherntheorie und ihre Anwendung in Modell-Analysen der Diskursbereiche Geistestätigkeit, Wirtschaft, Wissenschaft und Religion. Hamburg: Kovač, 2003.

KNOBLOCH, Clemens. Hermann Paul und die Sprachphilosophie. KODIKAS / CODE Ars Semeiotica, v.36, n.3-4, p. 257-268, 2013.

KÖVECSES, Zoltán. Metaphor and Emotion. Language, Culture, and Body in Human Feeling. Cambridge: Cambridge University Press, 2003.

LAKOFF, George. Women, Fire and Dangerous Things: What Categories Reveal about the Mind. Chicago: University of Chicago Press, 1987.

LAKOFF, George; JOHNSON, Mark. Metaphors We Live By. Chicago: The University of Chicago Press, 2003 [1980].

LAKOFF, George; JOHNSON, Mark. Philosophy in the Flesh. The Embodied Mind and its Challenge to Western Thought. New York: Basic Books 1999.

LANGACKER, Ronald W. Essentials of Cognitive Grammar. Oxford, New York: Oxford University Press, 2013.

MAUTHNER, Fritz. Wörterbuch der Philosophie. Band 1. Leipzig: Meiner, $1923[1910 / 11]$.

MOUTON, Nicolaas T. Ossthuizen. Metaphor, empiricism and truth: A fresh look at seventeenth-century theories of figurative language. In: BURKHARDT, Armin; NERLICH, Brigitte (Org.). Tropical Truth(s). The Epistemology of Metaphor and other Tropes. Berlin, New York: Walter de Gruyter, 2010. p. 23-49.

NERLICH, Brigitte; CLARKE, David D. Mind, meaning and metaphor: the philosophy and psychology of metaphor in 19th-century Germany. History of the Human Sciences, v.14, n.2, p. 39-62, 2001. 
OSTHOFF, Hermann; BRUGMANN, Karl. Morphologische Untersuchungen auf dem Gebiete der indogermanischen Sprachen. 1. Theil. Leipzig: Hirzel, 1878.

PAUL, Hermann. Ueber die Aufgaben der wissenschaftlichen Lexikographie mit besonderer Rücksicht auf das deutsche Wörterbuch. Aus den Sitzungsberichten der philosoph.-philolog. und der histor. Classe der K. bayer. Akad. d. Wiss. H. I. München. Sitzung vom 3. Februar 1894, p. 53-91, 1894.

PAUL, Hermann. Prinzipien der Sprachgeschichte. Tübingen: Max Niemeyer Verlag, 1995 [1886].

PAUL, Hermann. Princípios Fundamentais da História da Língua. Lisboa: Fundação Calouste Gulbenkian, 1970 [1886].

PÖRINGS, Ralf; SCHMITZ, Ulrich. Sprache und Sprachwissenschaft. Eine kognitiv orientierte Einführung. Tübingen: Gunter Narr Verlag, 2003.

SCHRÖDER, Ulrike. Antecipações da metáfora cotidiana nas concepções de Hans Blumenberg e Harald Weinrich. Revista de Estudos da Linguagem, v.16, n.2, p. 39-54, 2008.

SCHRÖDER, Ulrike. A Mesclagem Metafórica de Fauconnier \& Turner e nas teorias de Karl Bühler e Wilhelm Stählin: antecipações e complementos. Revista da ABRALIN, v.9, p. 129-154, 2010.

SCHRÖDER, Ulrike. Kommunikationstheoretische Fragestellungen in der kognitiven Metaphernforschung. Eine Betrachtung von ihren Anfängen bis zur Gegenwart. Tübingen: Gunter Narr Verlag, 2012.

SCHRÖDER, Ulrike. A abordagem cognitiva da metáfora em perspectiva pragmática nos séculos dezoito e dezenove: as contribuições de Lambert e Wegener a discussões atuais. ALFA: Revista de Linguística, v.58, n.1, p. 115-136, 2014a.

SCHRÖDER, Ulrike. Rediscovering the cognitive-semiotic and cognitivepragmatic approaches to metaphor in the work of Johann Heinrich Lambert and Philipp Wegener. metaphorik.de, v.25, 2014, p. 79-102, 2014 b.

SCHRÖDER, Ulrike. Uma volta para as fundamentações filosóficas de uma teoria cognitiva da metáfora. Domínios da Lingu@gem, v.11, n.1, 2017, p. 34-62. WEGENER, Philipp. Untersuchungen über die Grundfragen des Sprachlebens. Amsterdam: John Benjamins, 1991 [1885].

Recebido em: 31/07/2019

Aceito em: 30/11/2019 